\title{
TWEEDE VOORBEELD VAN ANTWOORDE
}

\section{Doel:}

Wat beoog $\mathrm{u}$ met $\mathrm{u}$ prediking? Verkondiging van die hele raad van God aan sy gemeente. Om die Woord eenvoudig en aktueel oop te maak om toe te pas.

\section{Tekskeuse}

1.1. Hoe kom $\mathrm{u}$ tot die keuse van 'n teks?

1.1.1. Deur gereelde stelselmatige Bybellees? Ja.

1.1.2. Deur aandagtige lees van koerante? $J a$.

1.1.3. Deur die soek van 'n teks in vermoedelik toepaslike gedeeltes n.a.v. die sg. kerklike jaar? Ja.

1.1.4. Deur die lees van homiletiese werke? Ja.

1.1.5. Deur gesprekke met lidmate en versoeke van hulle kant i.v.m. Skrifdele of probleme? Ja, by uitsondering.

1.1.6. Deur beplande Bybellees saam met verklarende aantekeninge, parafrases, kommentare, ens.? $\mathrm{J} a$.

1.1.7. Laat $u$ u ook lei deur die pastorale behoeftes van die gemeente? Ja.

1.2. Enige ander wyse? Spesifiseer asseblief. Teologiese studie; Teologiese tydskrifte wat uiters belangrik is. Vanuit die ervaringslewe van die week, omdat wat ek ervaar het ander ook ervaar het; radio-oordenkings; Bybelse dagboeke; reekse prediking oor bepaalde boeke.

\section{Die inleiding en slot van die preek}

2.1. Wat beoog $\mathrm{u}$ met die inleiding en slot van $\mathrm{u}$ preek? Inleiding: om die gemeente so gou moontlik by die sentrale gedagte te bring en wel op 'n prikkelende wyse. Slot: om die preek skerp rondom die sentrale gedagte af te sluit.

2.2. Watter vereistes stel $u$ vir die inleiding en slot? Albei moet so kort moontlik wees en aansluit by vrae en probleme wat in die gemeente leef. Die inleiding kan soms agtergrond gee, maar die slot moet altyd die gemeente in die oog hê.

2.3. Watter gevare meen u moet vermy word by die inleiding en slot? (1) Wydlopigheid. (2) Teologisering. (3) Redeneertrant. (4) Syspore. (5) Gebrek aan doelbewuste, logiese bou. (6) Cliches, stoffeerdery en sukkelry.

2.4. Watter lengte ag u geskik vir die inleiding? Dit hang van konteks af, maar nooit langer as enkele minute nie.

2.5. Hoe belangrik ag u die inleiding en waarom maak u die bewering? Die inleiding is van beslissende belang omdat dit die basis vir kommunikasie bewerkstellig of verongeluk.

2.6. Watter soort inleidings het $\mathrm{u}$ al oor die radio of elders gehoor waarteen u miskien wil waarsku? (1) Aanlope met oorbekende stof of herhaling van die Skriflesing. (2) Aanvallende en on- 
simpatieke ,holier than you". (3) Ongemotiveerde, kunsmatige of gekunstelde inleidings. (4) ' $n$ Kort opsomming van die inhoud. (5) Inleidings wat nie op die tema afstuur nie.

2.7. Watter waarde ken $u$ toe aan die slot in die geheel van die preek en hoe probeer $\mathrm{u}$ dit verwerklik? Die slot moet nie 'n item op homself word nie; die preek vinnig en sterk sluit deur die hoofgedagte final in die situasie van die gemeente te stel.

\section{Tema en verdeling}

3.1.1. Wat is 'n tema t.o.v. 'n preek? Hieroor heers baie verwarring. Dit behoort ' $n$ bepaalde gedagte in die teks te wees. Die een sien daarin egter ' $n$ onderwerp uit die teologie of uit die lewe gegryp en ' $n$ ander selfs 'n greep van die prediker.

3.1.2. Wat is 'n tematiese preek? ' $n$ Kapstokpreek waar ' $n$ idee van die prediker of ' $n$ onderwerp uit die lewe as ' $n$ preek aangedien word met so ' $n$ bietjie Bybelsous.

3.1.3. Definieer asseblief die begrippe: tema; hoofgedagte; sentrale gedagte; eenheid van die preek. Hierdie begrippe is sinonieme en dui aan wat 'n preek 'n preek maak. Daarin trek alles wat die preek wil sê, saam. Die eksegese word doelbewus gebruik om dit te ontclek.

3.2. Hoe kom $\mathrm{u}$ tot die verdeling van u preek? Ek het aanvanklik die hoofgedagte oordink en "kante" gesoek om dit toe te lig. Tans vind ek dat analise van die teks die fasette vir hantering van die hoofgedagte gee.

3.3. Gee u voorkeur aan:

3.3.1. Enkelversprediking, perikoop, homilie, kaleidoskopiese prediking, ,verrassende" prediking waarin die tema eers teen die einde uitkristalliseer? Enige vooroordeel is gevaarlik t.o.v. vers, perikoop of selfs verskillende Skrifgedeeltes as teks. Daar word soms gesondig met oorryk-preke wat te veel wil gee en uit reaksie met te kort en afgeskeepte preke. Die opsetlike metodes van „kaleidoskoop" en ,verrassing" bemoeilik op die lang duur die taak van die prediker.

3.3.2. Watter opvatting huldig $u$ oor die probleemstelling in $b g$. (3.3.1.) vervat? Kaleidoskopiese prediking gaan uit van die mens en sy lewe i.p.v. God en sy Woord. Die "verrassing" wat die dominee beoog val baie keer plat en wek op sy simpatiekste 'n glimlag by party hoorders. Die element van „vermaak" veroor. saak dat meer op die prediker as op die preek gelet word.

3.3.3. Hoe gaan $u$ te werk wanneer in die teks, perikoop of homilie meer as een hoofgedagte vervat is? Is 'n perikoop nie ook 'n teks nie? Het die teks nie 'n, ,hoofgedagte" nie? Selfs 'n gedeelte van 'n vers kan 'n teks wees.

3.4. Hoe bewoord $u$ die hoofgedagte:

3.4.1. Deur die gangbare idioom (met voorkeur aan die moderne taalgebruik) in ag te neem? $J a$.

3.4.2. Deur soveel moontlik tekswoorde feitlik as slagspreuke te gebruik? By uitsondering wanneer dit pas.

3.4.3. Deur bepeinsing van die eksegese om so te kom tot formu- 
lering van die tema uit $\mathrm{u}$ begrip van die inhoud van die teks? $\mathrm{Ja}$, mits 3.4.1. in ag geneem word.

3.4.4. Deur 'n tema aan 'n kommentaar of homiletiese werk te ontleen? Dit gebeur ook!

3.4.5. Wat is u eie metode? Hoofsaaklik maar volgens pt. 3.4.1. en 3.4.3.

3.5. Oor die verdeling en sg. "punte" in die preek bestaan daar uiteenlopende menings.

3.5.1. Wat is u mening daaroor? Punte moet nie ' $n$ doel op homself wees nie - maar sonder logiese bou is daar geen preek in die ware sin van die woord nie. 'n Preek het "fasette".

3.5.2. Wat dink u van die eise van logika vir die bou van 'n preek? Dis belangrik, mits ons die redenering en teologisering vermy. Onlogiese afleidings of konklusies skok die vertroue in die gesag van die prediking.

3.5.3. Indien $u$ wel met "hoeke van benadering" of ,punte" in $u$ preek wil reken, hoedanig moet dit wees en aangewend word? Dit moet uit teks voortvloei, 'n eenheid vorm - onderling sowel as met tema. Dit moet korrek, gebalanseerd en met plan aangewend word. Die preek is 'n gebou met fondament, mure en dak.

3.5.4. Watter ander kenmerke het die bou van 'n preek? (1) Die prediker moet presies weet wat hy wil kommunikeer, waar hy vertrek en waar hy met die preek heengaan. (2) Versorging van elke woord en sin. (3) Eenvoudige, natuurlike duidelikheid.

3.6. Gee asseblief u gedagtes i.v.m. herhaling in die prediking?

3.6.1. Die rede vir herhaling: (1) $\mathrm{Om}$ ' $n$ bepaalde saak tuis te bring, kan herhaling aangewend word. (2) Dikwels kom dit egter a.g.v. onrypheid van die preek, onsekerheid of slordige gewoontevorming.

3.6.2. Die plek van doelbewuste herhaling: As illustratiewe beklemtoning; as doelbewuste geleentheid vir die hoorder om „op te vang"; as uitsondering.

3.6.3. Die gevare van onbewuste herhaling. Die prediker voel nie tevrede nie en weet nie waarom nie. Die gemeente skakel af en verleer om te luister. Die preke word eindelose sirkels.

3.6.4. Hoe kan onnodige herhaling vermy word? Deur preke volledig uit te skryf. Die sondaars het net 'n papiertjie op die preekstoel. Die uitgeskrewe preek moet krities tydens die voorbereiding geredigeer word om herhaling te vermy.

\section{Explicatio}

4.1. Wat hou die explicatio vir $u$ in?

4.1.1. 'n Onderwerp wat $u$ uit 'n teks probeer haal? Nee.

4.1.2. 'n Teks wat $u$ in sy logiese sinsverband probeer „oopmaak"? $\mathrm{J} a$.

4.1.3. 'n Bepaalde Skrifgedeelte (teks of perikoop) wat u wil „oopmaak"? Ja, kyk 4.1.2.

4.1.4. 'n Bepaalde boodskap wat u uit die teks of met die teks probeer bring? Die begrip „boodskap" klink vir my Deisties. 
4.1.5. Hou dit vir $u$ iets anders as bg. in? Spesifiseer asseblief. Vir my bevredig die begrip "Woord van God" meer as "teks" of „perikoop". Dit is die wesenlike wat gepreek word.

4.2. Wat is $u$ evaluering van eksegese, openbaringsgeskiedenis, kanonlek en dogmatiek t.o.v. die explicatio? Al vier het groot nut afhangende van tekskeuse, moet altyd as agtergrond by die eksegese dien, maar nooit as sodanig preekstof word nie.

4.3. Wat is u mening i.v.m. die leeraspek (didaskein) in die prediking? Hoe gaan $u$ te werk om dit in die prediking te verdiskonteer? Prediking is lering. Kyk Ef. 1 : 16-23; 4 : 11-16. Hier het die Kategismusprediking as belydenis van die Skrif sy plek. Die leringe moet egter met motivering gebring word. bv. ' $n$ preek oor Sondag 8 moet deurtas na die Jehova-getuies, ens.

4.4. Stel $u$ 'n prioriteit tussen explicatio en applicatio in u prediking? Motiveer asseblief. Nee, wanneer prediking die tuisbring van Gods Woord is, kan die twee aspekte nie geskei word nie.

4.5.1. Watter kommentare gebruik u i.v.m. die explicatio? (Noem die werke op u rak met die oog op statistiek). Calvyn, Commentaar op O. en N.T. (Kok, Kampen), Korte Verklaring (Kok, Kampen), Kittel.

4.5.2. Watter van bg. kommentare wil u sterk aanbeveel? Grammatiese kommentare en Lexicons en sinverduidelikende kommentare soos Calvyn.

4.6. In die lig van bg. (4.1-4.5.) hoe moet die verklaring na $u$ mening plaasvind? Eenvoudig. Duidelik. Sinvol.

4.6.1. Watter kenmerke het 'n ,geslaagde" preekverklaring? Dat volwassene en kind, geleerd en ongeleerd, die Woord van God weer nut vir hulle eie lewe opvang.

4.6.2. Waaraan kan 'n mens minder geslaagde verklaring van 'n preek onderken? Vaaghede, swewend en onvolledig. ' $n$ Teks wat los van die Skrifverband soos ' $n$ vlieër in die lug hang. Self kom $j y$ agter wanneer $j y$ 'n preek na mande herlees hoe onduidelik, onryp en impaktloos dit was. Jy kom dit nie dadelik agter nie, omdat die preekmaak jou lewendige agtergrond gee, wat die gemeente nie het nie.

\section{Die Applicatio}

5.1. Watter rol speel die toepassing in $u$ hele proses van preekmak? Sonder toepassing is daar geen preek nie. Die preek is "So sê die Here" - en wat die Here sê is van toepassing.

5.1.1. Soek $u$ stof omdat $u$ 'n sekere lig op 'n bepaalde probleem wil werp - ongeveer soos 'n dokter wat na diagnose medisyne vir die kwaal probeer vind? Ja, soms.

5.1.2. Verklaar u die teks (perikoop) en laat dan die toepassing oor aan gedagtes wat in die proses van verklaring gebore word? Nee.

5.1.3. Watter ander eie metode wend $\mathrm{u}$ aan? Die preek vereis dat jy op die eietydse en plaaslike konsentreer terwyl jy ekse. gese doen.

5.2.1. In hoeverre moet 'n prediker sy toepassing aanpas by die smaak van die gemeente? (Bv. sal $u$ in 'n preek oor Sondag 42, 
vr. III H.K. op die platteland lone van plaasarbeiders aanraak of dit liefs t.w.v. stigting vermy?) Dit behoort nie te gebeur nie, maar gebeur tog omdat mens "populêr" wil wees en nie in gedrang wil kom nie.

5.2.2. Hoe sien $u$ die verhouding en probleem tussen toepassing wat stig en ontstig i.v.m. die manier waarop die prediker dit bring? Die toepassing ontstig wanneer die gemeente intuitief aanvoel dat die dominee sy tradisionele of moderne opvattings aan hulle voorskryf, iemand uitsonder en aanpak, of die dominee "donderslae"-preek op ander as hyself.

5.3. Hoe sien $u$ die gerigtheid van die prediking op die gemeente t.o.v. eenheid en differensiasie (bv. ouderdom, beroep, verskil in begripsvermoë, psigologiese gevarieerdheid, ens.)? Mens moet met hierdie verskillende groepe rekening hou, hoewel nie in elke preek met almal nie. Prediking het altyd ' $n$ universele inslag, al sou elke kind nie alles verstaan nie. Die individuele pas in die pastoraat.

5.4. Wat beskou u as die „eietydse" van die mens en wêreld van vandag? Die tipiese is die haastigheid en dramatiese inslag. Die tegniek en onderwys het hom ' $n$ mens vir die natuur gemaak en sy blik van God afgetrek. Wanneer die eietydse tot norm gemaak word, verloor die prediking en Skrif sy gesag.

5.4.1. Hoe probeer $u$ op hoogte kom en bly met die hedendaagse lewensgevoel, kultuurpatroon en die besondere pastorale probleme van ons tyd, ens.? Leeswerk. Kommunikasie met andersdenkendes, mits jy jouself en jou eie positief en negatief kan waardeer.

5.4.2. Hoe gebruik u dit met die oog op u toepassing? Die eksistensiële benadering is nodig en die hele mens moet voor Gods Woord geplaas word, saam met jou as prediker.

5.5. Wat is u beskouing oor die moderne gedagtes t.o.v. aktueler prediking bv. die dialogiese metode (bv. dat die prediker in sy preek ook vrae stel wat leef in die harte van die hoorders; dat hy in lyn met die moderne lewensgevoel meer soekend preek en nie ,aanseggend" nie); op die jeug gerigte prediking; diskussie na die diens oor die preek; Bybelstudie i.p.v. prediking; enige ander gangbare opvatting wat $u$ teëgekom het en in hoeverre u dit positief of negatief waardeer? Die moderne mens is ' $n$ soeker en moet nie nog deur preke meer an die soek raak nie. HIy hardloop gou na die „spesialis". - Hy soek ook sekuriteit in die prediking. Ongelukkig neig hy horisontaal, al rondom homself. As die prediking ' $n$ horisontale dialoog word, imponeer dit tydelik, verloor geleidelik sy gesag en kan dan geen sekerheid meer gee nie.

5.6.1. Die prediker staan in diens van die gemeente en ontvang sy roeping van God. Hoe en in hoeverre identifiseer hy hom in die prediking met sy roeping deur God, en hoe en in hoeverre identifiseer hy hom in die prediking met die gemeente? Die prediker bly sondige en beperkte mens. Tog is hy ook die dienaar wat die Woord van God bring. Hy moet hom biddend en bewoë afvra war gee God hom mandaat en waar tree hy op 
as mondstuk van sy kultuur, opvoeding, en menslikheid.

5.6.2. Hoe vermy die prediker die gevaar dat hy die hoorders aanstoot gee deur 'n houding van „afstand", „heilig-wees”, afsydigheid, ens.? Deur hom soos 'n gewone, feilbare mens te gedra, wat ook mar van genade leef, d.w.s. deur empatie, simpatie en deurleefde solidariteit.

5.6.3. In hoeverre het die prediker te doen met die probleem dat hy slegs in 'n beperkte veld kan toepas (bv. Bybellees, gebed, bydraes, kerkbesoek, ens.) - en sodoende nie die leefwêreld van die lidmate bereik nie? Hoe kan hy dit vermy? Baie faktore dryf predikante terug op die kort front van die metodisme, sodat al die toepassing gerig word op huisgodsdiens, kerkbywoning, kerkbydraes, gewilligheid vir ampsdiens. God en kerk word min of meer geïdentifiseer, terwyl die lewe (van elkeen anders) godsdiens moet wees.

5.6.4. Hoe kan die indikatief van die genade, die imperatief van die dankbaarheid en die bevindelike in die toepassing tot sy reg kom? Eers moet die genade self entoesiasties beleef word en vir die gemeente aangesê word (indikatief) en dan daarop die vraag hoe raak dit my as klerk, arbeider, skolier? Daarom luister die gemeente nie graag na preeklees nie.

\section{Die Homiletiek as vak}

6.1. Is daar 'n bepaalde homiletiek wat uit $u$ opleiding stam of wat u as gangbaar ,gereformeerd" beskou waarmee $\mathrm{u}$

6.1.1. Definitief gebreek het? Ja. (1) Die idee van die preek as "leerredene" wat dogmaties reg moet wees maar die lewe nie raak nie. (2) Die analitiese preek. (3) Die preek as 'n produk van my opleiding.

6.1.2. Waarby $u$ hou om nie aanstoot te gee nie, hoewel dit $u$ nie bevredig nie? Nee.

6.2. Watter "leemtes" merk u by uself en ander gereformeerde predikante op wat as 'n kenmerkende opleidingsleemte bestempel kan word? By baie predikante is die prediking nie aktueel genoeg nie. In die wereld is menseverhoudinge aktueel en dit word aan die politici oorgelaat, moontlik a.g.v. die kringe-leer in die wysbegeerte. ' $n$ Tipiese statiese begripsmatige taalgebruik, bv. Ons troos is i.p.v. Christus troos ons... Daar bly iets van 'n akademiese stempel op die kommunikasie rus, moontlik a.g.v. Nederlandse religieuse werke.

6.3. Is daar leemtes wat $\mathrm{u}$ agterna in $\mathrm{u}$ eie homiletiekvorming ontdek het? Ja, om los te kom van, ,boeke" en self met die Skrif besig te raak en „boeke" eers daarna as hulp by te bring. Die homiletiekvorming bring nie genoeg oefening en begrip hoe om die brë̈ teologiese vorming - eerder as boeke - aan te wend nie. Mens begin met 'n slaafse afhanklikheid van boeke.

\section{Formeel}

7.1. Wat is $u$ mening oor die taalgebruik van predikante in terme van die volgende leidinggewende woorde, predikante-taal; teologiese vaktaal; kanseltaal; tale Kanaäns; cliches; gebruik van 
die abstrakte selfstandige naamwoord of konkrete werkwoord ens.? Oor algemeen hoor ' $n$ mens in jou eie taalgebruik baie maal die taal van die kommentaar wat jy geraadpleeg het. Daar word te eensydig van jou woordeskat uitgegaan en te min van dié van die hoorders. Veral kinders verstaan nie abstrakte begrippe nie.

7.2.1. Watter rol speel taal en tipe taalgebruik in die kommunikasie? Baie belangrik. Daarsonder is die ontmoeting (erediens) dood.

7.2.2. Hoedanig bevorder $u$ kommunikasie in $u$ prediking deur te konsentreer op u taalgebruik en -versorging? Mens probeer varieer: skilder, direkte styl. Mens probeer negatiewe en ontkennings, redeneer met want, omdat en indien vermy, ens.

7.3. Watter kenmerk, meen $u$, moet die taal vir die prediking hê en watter gevare moet vermy word? Kort sinne. Eenvoudige, beskrywende, lewende taal sonder platheid, breedsprakerigheid, jouself in die rede val, bewuste "mooi" doen, effek-bejag ens.

7.4. Watter praktiese wenke kan vir die bevordering van preektaal in ag geneem word? (Bv. lees van digbundels, voorbeelde van Okke Jager, die gevaar van die redeneertrant met woorde en sinne soos "want" en „omdat" ens.? Digbundels, preekbundels, koerante, taal handboeke (idiome ens.) en woordeboeke. 'n Goeie voorbeeld kan baie sè. Tog net nie mooidoenery, opsetlike "snaaksighede" of "nuwighede" wat vermaak i.p.v. preek nie.

7.5. Wat is u ervaring (voordele en nadele) t.o.v. preke sonder skets; preke met 'n korter of langer skets; preke wat volledig uitgeskryf is? Sketspreke is verkieslik. Dit verhoed dat die preek 'n leespreek word. Die beste is waarskynlik 'n vrywel volledige uitgeskrewe preek op die teenbladsy opgesom.

7.6. Watter probleme moet $u$ telkens weer in $u$ eie hart en lewe oorkom om te kan preek? (1) Onwaardigheid by die taak om ' $n$ magtige boodskap van lewe en dood te bring. (2) Mens se stryd teen gemaksug wat maar "maklik" en "gou" 'n preek wil maak. (3) Toenemende onbetrokkenheid van gemeentelede by die prediking.

7.7. Watter metodes stel $u$ in werking om $u$ prediking te evalueer (bv. terugspeel op bandopnemer; gesprek met kerkraadslede of gemeentelede, ens.)? (1) Kritiese selfontleding. (2) Huisbesoek. (3) Gesprekke met mede-predikante oor angste en probleme i.v.m. my prediking.

7.8.1. Maak $\mathrm{u}$ in die reël elke week twee nuwe preke? Ja, behalwe wanneer in ' $n$ ander gemeente opgetree word.

7.8.2. Wat is $u$ mening i.v.m. die herhaling van 'n „ou" preek? Dit kan eintlik slegs gebeur wanneer weer eksegese gedoen en elke sin verantwoord word. So word die preek van 'n „ou preek” vir 'n mens self nuut.

7.8.3. Hoeveel tyd bestee $u$ weekliks aan die voorbereiding van $u$ preke? Dit neem my minstens $6 \longrightarrow 8$ uur vir 'n preek.

Voetnoot: Hierdie antwoorde is effens geredigeer uit meer as een antwoordlys. - Red. 